\title{
MODELING THE EFFECTS OF ROAD CONSTRUCTION ON THE ATTRACTION AND REGIONAL DISTRIBUTION OF FOREIGN INVESTMENT IN CHINA*
}

\author{
by Yoshitsugu HAYASHI $^{* *}$, Yang Zhong-Zhen ${ }^{* * *}$
}

\section{Background}

During the period 1980-1993, China invested heavily in road construction, especially in expressway construction. Simultaneously, with its "reform and open" policy, China has allowed foreign investment to enter. In China the transport infrastructure is one of the most important means for promoting regional economies and foreign investment. So both national and local governments pay much attention to road construction when they tend to attract much more foreign investment. Foreign investors also select locations according to the condition of the transport infrastructure. In order to optimize road investment to supply a suitable transport infrastructure for the economy, it is necessary to analyze the effects of road construction. This analysis should also have the function of helping levy fair taxes on beneficiaries with respect to benefits gained.

Effects' analysis of road construction in China is currently limited to the direct effects, neglecting indirect effects such as impact on foreign investment, land-use, production and employment. Not just the direct impact, but also the indirect one is very important. For example, road construction projects in a region can induce more foreign investment to this region, then the induced foreign investment will become the economic accelerator for this region. For this sort of reason, if the indirect effects are neglected, correct results can't be generated in cost-benefit analysis. However indirect impact is much more difficult for us to grasp and calculate. Especially because of Chinese economic characteristics, existing models developed in other countries can not be applied directly. So the aim of this study is to develop a model for estimating the indirect effects of expressway projects. With this model we can estimate the indirect effects of expressway, including attraction and the regional distribution effect on foreign investment in China.

\section{Relationship between Road Construction and Foreign Investment in China}

\section{(1) Economic Growth and Transport Situation}

Since 1980 China has become one of the countries with the fastest economic growth rate in the world. China's GDP grew at about an annual average $9 \%$ during the same period. Because of this fast economy growth the transportation volume also increased quickly. Figure 1 and Figure 2 show the GDP and transport volume in the study region respectively. From Figure 2 we can see that road transportation increased similarly with the GDP. On the other hand, railway transportation stayed at the same level during this period. The reasons for this symptom are

1) the burden of the railway in this region is too heavy for it to enlarge its operating volume,

2) the government encourages the use of roads instead of railways for short-distance transportation,

3) Because the railway is dominated by the government, it is difficult for users to use it. But the roads are so flexible that users can use them easily at any time.

Therefore after "reform and open", the users, especially the non-state owned enterprises such as foreign enterprises, would rather use roads because of their convenience and availability

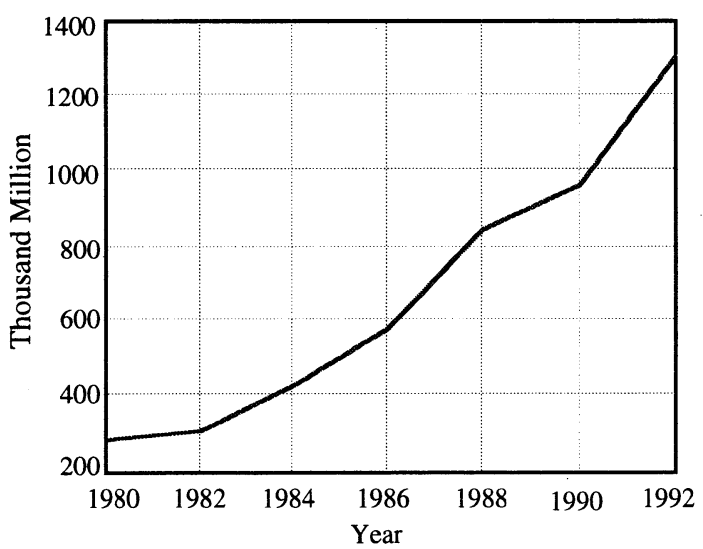

Figure 1 Annual Incremental Growthin in GDP in Liaoning

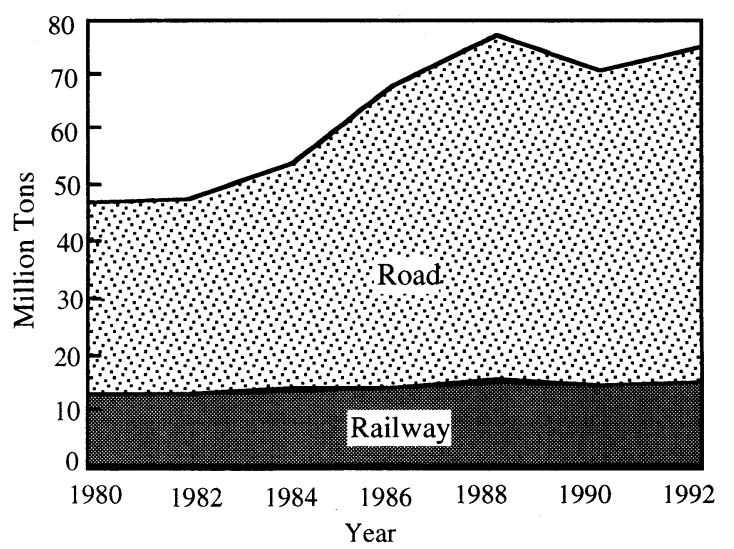

Figure 2 Freight Traffic by Models In Liaoning

${ }^{*}$ Keyword: Foreign Investment, Construction Effects, Attraction and Distribution

**Fellow Member of JSCE, Professor, Geotechnical \& Environmental Eng. , Nagoya University, Chikusa-ku, Nagoya 464-01 Japan

***Graduate student, Geotechnical \& Environmental Eng., Nagoya University, Chikusa-ku, Nagoya 464-01 Japan 


\section{(2) Expressway's Construction}

Because of its advantages, road construction in China is now booming. The high speed and capacity expressways have become very popular. Since the first expressway was built in 1988, the length of expressway in China has increased quickly. As shown in Figure 3, in order to provide good transport service for foreign investment as well as to match the policy of developing the coastal area first, the constructed expressways are mainly located in the Coastal Areas, furthermore almost all of their beginning points are harbor cities.

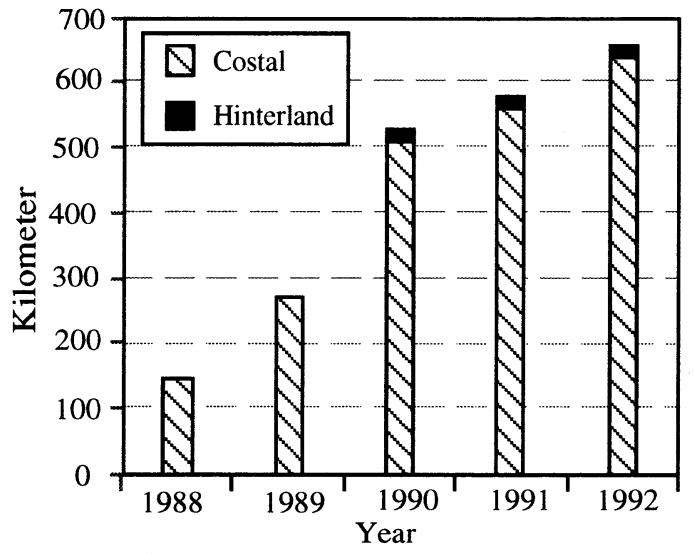

Figure 3 Distribution of Chinese Expressway

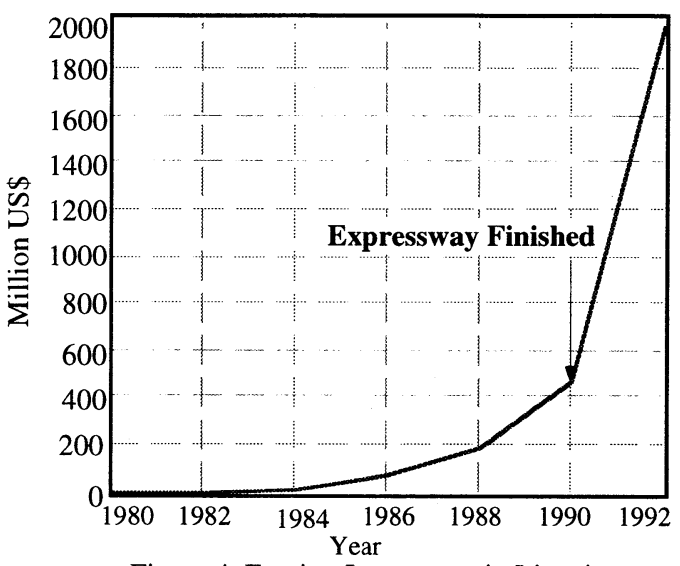

Figure 4 Foreign Investment in Liaoning

\section{(3) The Characteristics of Foreign Investment in China during 1980-1993}

From 1980, because of the "reform and open" policy, foreign investment began to enter into China. The investment in Liaoning Province has grown spirally as shown in Figure 4. The reasons foreign enterprises invest in China are manifold. The main reasons are as follows.

1) The developed countries are in the process of restructuring their economies. They want to transfer some industries outside. There is also a lot of surplus capital in the industrial countries.

2) The developed countries want to make use of the cheap labor and other production factors to make their products more competitive in the international market.

3) The 1.2 billion population means there are big markets in China. Whoever wants to exploit this large potential market must establish their companies or factories in China.

These are the main three location factors for foreign investment in China. Considering 1) and 2), the accessibility from the location sites to harbors is so important that at the beginning almost all of the foreign investment concentrated in coastal cities as shown in Figure 5. As the result of this concentration, the following problems appeared for foreign investors:

1) In coastal cities, production cost such as labor, land price and service price became expensive.

2) The production infrastructure which can be offered by coastal cities reached its limit.

3 ) It has become harder and harder for foreign companies to get their needed materials.

4) It is difficult for foreign companies to gain access to the domestic markets.

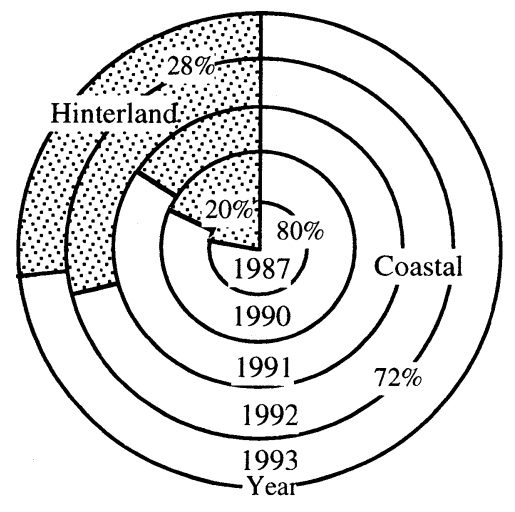

Figure 5 Foreign Investment in Liaoning

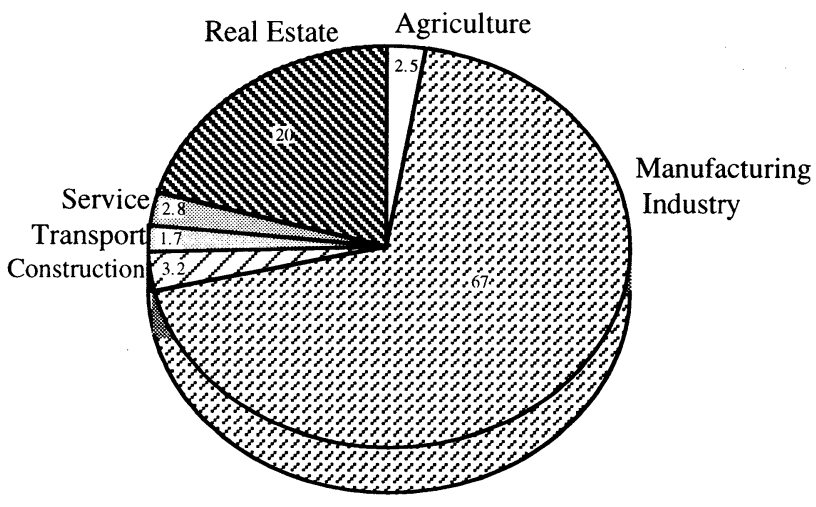

Figure 6 Shares of Foreign Investment in Each Field in Liaoning(1980-1993) 
On the other hand, the Chinese Government has prompted its "open" policies further. Since 1989, almost every city in Liaoning province has become able to introduce foreign investment by supplying favored treatment for foreign investors, such as tax exemption and free use of land. So afterwards, foreign investment began to disperse into the hinterland cities which offered good transportation conditions, rather than just concentrating in coastal cities. In this process the accessibility among the cities in a region has become very important for foreign investment. In this study we consider these two kinds of accessibility as the key attractive factors for foreign investment.

From Figure 6, we can observe another characteristic of foreign investment, that is, it is mainly concentrated in manufacturing industries rather than in other fields. This is also a reason why road transportation is very important for investment because the manufacturing industry requires much more transport activity than other industries.

\section{(4) Effects of Expressway Construction on Foreign Investment}

Expressway construction can shorten the transport time and increase the transport convenience from city to city. This kind of transportation is a major production activity of enterprises. Especially for the foreign enterprises which are mainly manufacturing industries and import-export oriented, improvement of transport conditions can shorten the transport time and cost from other cities to coastal cities. As a result of expressway construction, both the accessibility among cities in this region and the accessibility of this region to the outside increased. From the above analysis, we can find that these kinds of accessibility have two effects on foreign investment and we can depict these effects of expressway construction on foreign investment as shown in Figure 7. We will format our model in Chapter 4 according to this analysis.

1) Generation (Attraction) Effect: Because of the rise in accessibility, the attraction of foreign investment will increase. More investment will be attracted into this transport improved region.

2). Distribution Effect: Not only because of the first kind of accessibility but also because of the rise of second kind, the attracted foreign investment will disperse into every city rather than just concentrating in one or two sites.

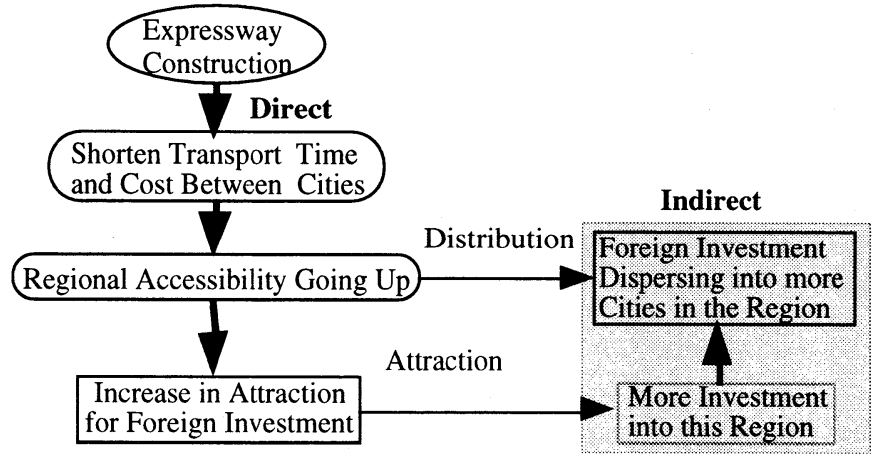

Figure 7 Effect of Expressway On Foreign Investment

\section{Analyzing Method}

We can analyze the effects of transport infrastructure at both micro and macro level. At the micro level we deal with individual observations on actors who are exposed to and hence affected by transport infrastructure. Micro study is normally related to survey methods( e.g. questionnaires, interviews, self-administration). It should be noted however, that acquiring this kind of information is costly and time consuming in China.

A central question in micro studies that aims to analyze the importance of infrastructure for economic development is to which extent the quality and quantity of infrastructure is an important location factor for a company. Besides, it is hardly possible for us to give an impression of possible effects in case of "infrastructure off situation". Furthermore, generation and distribution impacts are generally not distinguished ${ }^{1)}$.

The class of macro approaches is not entirely separated from micro analysis, as macro studies are often based on aggregated results of micro-based surveys taken by the bureau of statistics of the Chinese central and local governments, but they are sometimes less costly and less time consuming than micro approaches. In this study we will use macro approaches because of this advantage. In our macro approaches, we employ two kinds of models: multiple-equation models and singleequation models. Multiple-equation models can be further subdivided into Input-Output models and General Simultaneous models.

These kinds of models make it possible to consider the various impacts of transport infrastructure on various regional profile elements. They are also able to capture the causal relations between infrastructure and regional development. But they also need a large amount of data. For example when analyzing effects at a macro level with the input-output method, an interregional input-output table must be needed.

The single-equation models used for infrastructure effects analysis can be based on different approaches viz., the Production Function approach and Location Factor approach. In the Production Function approach, we consider infrastructure investment as a production factor in order to estimate the impact of transport infrastructure on regional production. In the Location approach, infrastructure plays a role - besides other factors - as a strategic location factor. 
In China, because the reform from planned economy to market economy has just been implemented for a few years, there is not plentiful data for us to use. Besides, the economy of China is still in a semi-planned and semi-market situation, the mechanism is very strange. Subject to this data limitation we develop a model based on single-equation approaches which can analyze the attraction and distribution effects of road infrastructure on foreign investment in China. Just with the data from the Statistic Bureau, we can make a simulation of this model. The case study region-Liaoning Province- is regarded as an "Open Region" in the Chinese Eastern Coastal area.

\section{Modeling Effects of Road Construction on Foreign Investment}

\section{(1). Attraction Effect}

As analyzed above, besides the economic and political reasons, the accessibility of a region is essential for foreign investors to locate. Hereafter, we suppose the attraction of a region for foreign investment is represented by the accessibility of this region. Furthermore the accessibility can be divided into two kinds: (1) accessibility to the outside of the region and, (2) accessibility between cities in the region. According to this assumption we model the attraction effect as follows;

\section{a) Accessibility to the Outside of the Region}

Accessibility to the outside is represented by the accessibility to the harbors of this region. Because foreign enterprises export $80 \%$ of their output, their production value can represent their transport volume from production location to harbors. The accessibility of this region to the outside can be modeled as equation (1).

$$
A c c=\sum_{i=1}^{N} \sum_{j=1}^{N 1} P_{i} F T_{i j} f\left(c_{i j}\right)
$$

Acc: Accessibility to the outside;

$P_{i}$ : Foreign enterprise production value in city $\mathrm{i}$;

$N$ : Number of city in the region;

$N 1$ : Number of harbor in the region;

$f\left(c_{i j}\right)=\frac{1}{c_{i j}^{\gamma}}:$ Transportation resistance ;

$F T_{i j}$ : Share of foreign enterprises' import-export freight in city i operated by harbor $\mathrm{j}, \sum_{j}^{N 1} F T_{i j}=1$

$c_{i j}$ : General transportation time between city $\mathrm{i}$ and harbor $\mathrm{j}$ by road.

$\gamma:$ Parameter

The difference of accessibility to the outside between period $\mathrm{t}$ and period $\mathrm{t}-1 \Delta A c c$ would be calculated as equation (2)

$$
\Delta A c c=A_{c c}^{\prime} / A_{c c}^{t-1}-1=\sum_{i=1}^{N} \sum_{j=1}^{N 1} P_{i}^{t} F T_{i j}^{t} f\left(c_{i j}^{t}\right) / \sum_{i=1}^{N} \sum_{j=1}^{N 1} P_{i}^{t-1} F T_{i j}^{t-1} f\left(c_{i j}^{t-1}\right)-1
$$

b) Accessibility between Cities in the Region

Accessibility between cities should be represented by the ease of access to the products and material market. It can be considered as equation (3).

$$
A c c^{\prime}=\sum_{i=1}^{N} \sum_{j=1}^{N} Y_{i} Y_{j} f\left(c_{i j}\right)
$$

Acc : Accessibility between cities in this region

$Y_{i}, Y_{j}:$ GDP in city $\mathrm{i}$ and $\mathrm{j}$

$c_{i j}$ : General transport time from city i to city $\mathrm{j}$ by road.

$$
\Delta A c c^{\prime}=A c c^{i} / A c c^{i-1}-1=\sum_{i=1}^{N} \sum_{j=1}^{N} Y_{i}^{t} Y_{j}^{t} f\left(c_{i j}^{t}\right) / \sum_{i=1}^{N} \sum_{j=1}^{N} Y_{i}^{t-1} Y_{j}^{t-1} f\left(c_{i j}^{t-1}\right)-1
$$

$\Delta A c c^{\prime}:$ Change of total value of the accessibility between cities in the region between periods $t-1$ and $t$ c) Regional Attraction for Foreign Investment

According to the analysis in Chapter 2, the region's attraction for foreign investment is at positive proportion with its accessibility. We define the accessibility as the region's attraction for foreign investment as equation (5).

$$
A t t=\alpha A c c+\beta A c c^{\prime}
$$

Since we do not have enough data to estimate $\alpha, \beta$ of equation (5), we simply use equation (6) to carry out our calculation.

$$
\Delta A t t=\left(A c c^{t} / A c c^{t-1}-1\right)+\left(A c c^{t} / A c c^{t-1}-1\right)
$$


Att: The attraction of this region for foreign investment

$\Delta A t t$ :The change of $A t t$ between periods $\mathrm{t}-1$ and $\mathrm{t}$

$\Delta Z=\Delta A t t \times Z^{t-1}$

$Z$ is the foreign investment in this region, $\Delta Z$ is the change of foreign investment between periods $\mathrm{t}-1$ and $\mathrm{t}$.

$$
Z^{t}=Z^{t-1}+\Delta Z
$$

$Z^{t}$ : The due amount of foreign investment in period $\mathrm{t}$.

\section{(2) Distribution Effect.}

As locatable sites become more and more, foreign investment no long concentrates mainly in coastal cities as before. Investors would choose location where they can obtain the maximum utility based on the Random Utility Theory. In China the foreign investment location factors are assumed as follows. $\left.{ }^{5}\right)$

1).Transportation time to harbors $T$ which perhaps is the most different production cost in the assumption that all the products of foreign investment are exported through harbors,

2).Telephone ownership $E$ (telephones $/ 1000$ persons) which can represent the live and production condition for foreign enterprises which heavily depend on international communication

(3) Labor resources and market volume are represented by the population within working age $L$.

It is thought that the wage, land rent and favorable policies are also the essential factors in location behaviors, however they are not different obviously between cities in the case study area. For example, the margin between the highest and lowest wages is just about $40 \%$, and in every city there are some similar favorable policies for attracting foreign investment such as the free use of land and exemption from business tax in the first three years. Therefore these kinds of factors could not be used when distributing the foreign investment among cities. As the result we model the location glamorous $\pi$ of each city as equation (9).

$$
\pi_{i}=\pi_{i}\left(T_{i}, E_{i}, L_{i}\right)=\alpha T_{i}^{\beta 1} E_{i}^{\beta 2} L_{i}^{\beta 3}
$$
respectively.

So the probability of investing in city $i$ and the investment amount can be calculated as equation (10) and (11)

$$
\begin{aligned}
& \operatorname{Pr}_{i}=\frac{\exp \left(\mu \pi_{i}\right)}{\sum_{j=1}^{N} \exp \left(\mu \pi_{j}\right)} \\
& Z_{i}=\operatorname{Pr}_{i} \cdot Z \\
& \operatorname{Pr}_{i}: \text { probability of investing in city } \mathrm{i} ; Z_{i}: \text { the foreign investment amount in city } \mathrm{i} .
\end{aligned}
$$

\section{(3) Effects of Expressway Construction on Foreign Investment}

With models in this Chapter we can estimate the amount of foreign investment of period $t$ from the data of period $t-1$. In order to estimate effects of expressway construction, we can divide period t into two situations: with and without an expressway. In each situation we can obtain $Z^{t}$ and $Z_{i}^{t}$ respectively. The different parts $\Delta Z=Z^{t 1}-Z^{t 0}$ and $\Delta Z_{i}=Z_{i}^{t 1}-Z_{i}^{t 0}$ are considered to be the effects of the expressway on foreign investment. $t 1$ and t0 respect the situations with and without an expressway in period $t$ respectively.

\section{Case Study}

\section{(1) Study Area and Data:}

The study area, Liaoning province, is located in the north-east area of China (Figure 8). In this region there are 11 cities and among which four are harbor cities. One of the harbors-Dalian harbor, is the third largest in China in term of trade tonnage and was nominated as one of the earliest 14 Opening Coastal Cities in 1984.

The first and longest expressway in China was finished in 1990 between Dalian and Shenyang in this region. The target of this study is the new added foreign investment rather than the movement of the existing one. Because the foreign investors have been looking for the chance of entering China, when a good chance appears they will act immediately. This situation can be verified by Figure 5. It is reasonable to choose two years as the time span. Therefore we use 1990 as period t1, and 1992 as period $t$ to simulate. The data is mainly from Statistic Year Book of Liaoning (1991,1993 and 1994), but the roads' O-D transport time table between cities in 1990 and 1992 is from the Liaoning Highway Management Bureau. O-D transport time table between cities in 1990 can be used as the data for the case without the expressway. O-D transport time table in 1992 can be used as the data for the case with the expressway. We use $\gamma$ as a given one $(\gamma=2)$ and based on the scale of the city, we gave out the intra-city transportation cost (time) as follows:

City with the population over 1 million: $c_{i i}=0.7$ hour

City with the population between 1 million and 0.5 million: $c_{i i}=0.5$ hour 
City with the population under 0.5 million: $c_{i i}=0.3$ hour.

We use 1993 data to estimate parameters of models such as the Utility Function, Investment-Output function etc.

\section{(2). Structure of the Simulation and its Results}

The flow of the simulation is shown in Figure 9. In order to calculate accessibility, we have to calculate ImportExport distribution model in step 1, Investment-Output model in step 2 and GDP model in step 3. With the accessibility calculated in step 4, we can calculate the attraction model in step 5 and distribution model in step 6 . We use steps 7 and 8 to joint the attraction model and the distribution model for iteration. Finally divide period $t$ into two kinds of situation - with and without an expressway to calculate the foreign investment respectively in step 10.

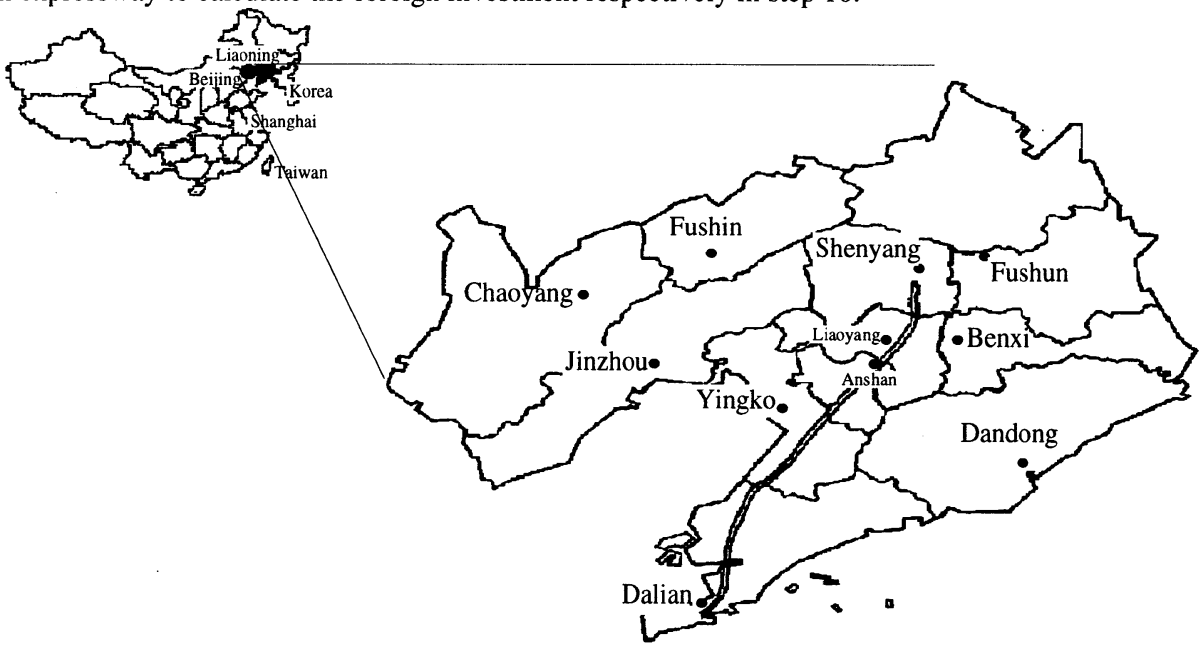

Figure 8 Location of Case Study Region in China

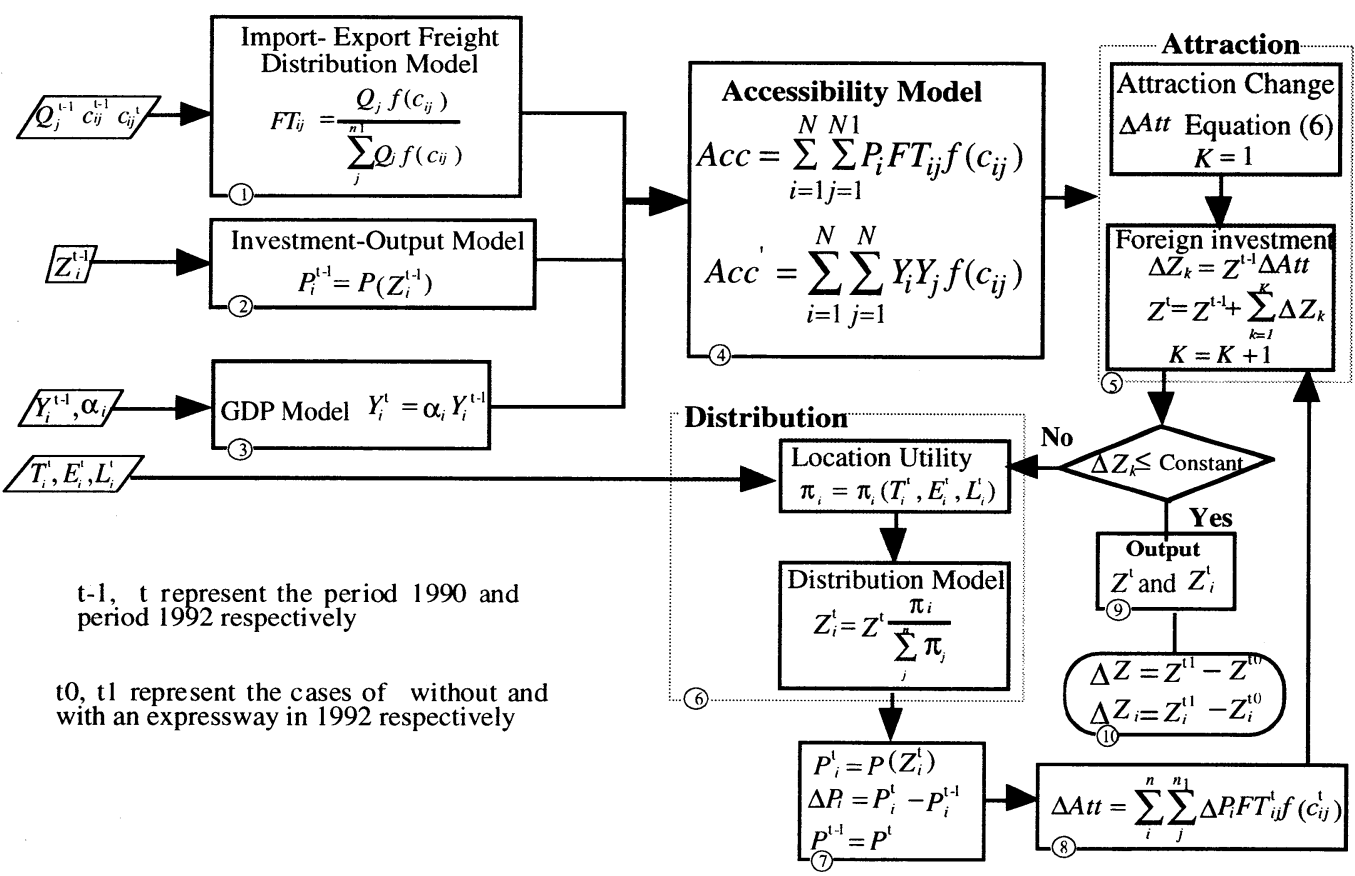

Figure 9 Simulation Flow of The Model

a) Foreign Enterprise Import-Export Freight Distribution Model (Step 1)

When foreign enterprises export or import product goods, it is obvious that they would choose a harbor according to the service level of the harbors as well as the transport cost from production locations to the harbors. But because in this study we did not collect enough detailed information about harbors, we estimate $F T_{i j}$ of 1990 by a macro method. In this model we 
take freight volume operated by a harbor as the indicator for its service level, and use transport time to a harbor for transport cost. We formulate the model as equation (12).

$$
\begin{aligned}
& F T_{i j}^{t-1}=\frac{Q_{j}^{t-1} f\left(c_{i j}^{t-1}\right)}{\sum_{j=1}^{n 1} Q_{j}^{t-1} f\left(c_{i j}^{t-1}\right)} \\
& \quad Q_{j}: \text { Total amount of import-export freight operated in harbor } \mathrm{j} \text {; } \\
& F T_{i j}^{t-1} \text { is interpreted as the probability of foreign enterprises in city i using harbor } \mathrm{j} \text { in period t-1 (1990) }
\end{aligned}
$$

Because we made 1992 the projected period t, $Q_{j}$ in 1992 is an unknown value. Thus when calculating $F T_{i j}$ of 1992 , we use $F T_{i j}$ of 1990 and the changed O-D transport time table. We formulate this as in equations (13) and (14).

$$
\begin{aligned}
& F T_{i j}^{t}=\frac{F T_{i j}^{\prime}}{\sum_{j=1}^{n 1} F T_{i j}^{\prime}} \\
& F T_{i j}^{\prime}=\frac{f\left(c_{i j}^{t}\right)}{f\left(c_{i j}^{t-1}\right)} F T_{i j}^{t-1}
\end{aligned}
$$

$F T_{i j}^{\prime}$ is the changed probability of foreign enterprises in city $\mathrm{i}$ using harbor $\mathrm{j}$ because of the transportation improvement. We adjust $F T_{i j}^{\prime}$ with the adjustment variable $\sum_{i=1}^{n 1} F T_{i j}^{\prime}$ to obtain the new probability of foreign enterprises in city i using harbor $\mathrm{j}$

\begin{tabular}{|c|c|c|c|c|}
\hline City Harbor & Dalian & Jinzhou & Yingkou & Dandong \\
\hline Shenyang & 0.90 & 0.01 & 0.08 & 0.01 \\
\hline Dalian & 0.99 & 0.00 & 0.01 & 0.0 \\
\hline Anshan & 0.86 & 0.01 & 0.12 & 0.01 \\
\hline Yingkou & 0.74 & 0.01 & 0.24 & 0.01 \\
\hline
\end{tabular}
in period t $F T_{i j}^{t}$. The calculated results of this model are given in Tables 1 and 2.

Table 1 Calculated Results of $F T_{i j}{ }^{\prime}$ (some cities)

\begin{tabular}{|c|cccc|}
\hline City & Dalian & Jinzhou & Yingkou & Dandong \\
\hline Shenyang & 0.88 & 0.01 & 0.09 & 0.02 \\
Dalian & 1.00 & 0.00 & 0.00 & 0.00 \\
Anshan & 0.84 & 0.01 & 0.13 & 0.02 \\
Yingkou & 0.59 & 0.01 & 0.39 & 0.0 \\
\hline
\end{tabular}

Table 2 Calculated Results of $F T_{i j}^{t-1}$ (some cities)

b). The Investment-Output Model (Step 2)

The output of foreign investment is a key factor when considering the accessibility to the outside. Foreign investors will actually estimate accessibility according to their output which results from their investment amount. The formation of an Investment-Output model is as equation (15). We use its logarithm formation (16) to estimate this model. The estimated results of parameters are given in Table 3 and Figure 10.

$$
\begin{aligned}
& P_{i}=\alpha Z_{i}^{\beta} \\
& \ln P_{i}=\alpha_{0}+\beta \ln Z_{i}
\end{aligned}
$$

Table 3: Estimated Parameters

\begin{tabular}{|c|c|c|}
\hline Parameter & $\alpha_{0}$ & $\beta$ \\
\hline Value & -0.82 & 0.96 \\
\hline T-value & 1.00 & 10.93 \\
\hline$R$ & \multicolumn{2}{|c|}{0.964} \\
\hline Sample & \multicolumn{2}{|c|}{11} \\
\hline
\end{tabular}

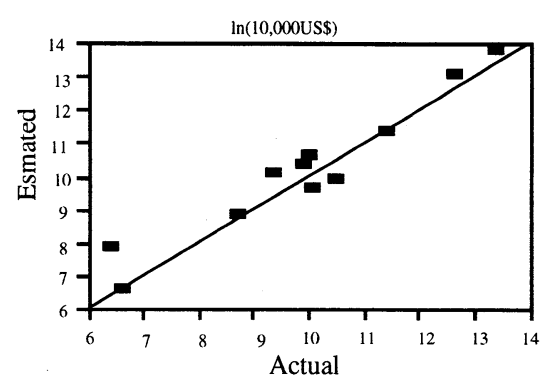

Figure 10 Comparison of Esimated and Actual Amount of Investment-Output Sub-model

Since in this simulation, the investment of 1990 has already accrued, $Z_{i}^{t-1}$ can be obtained easily from the Statistic Year Book of 1991. But the $Z_{i}^{t}$ is unknown. At first we use the accrued investment $Z_{i}^{t-1}$ as $Z_{i}^{t}$, and then as shown in Figure 9, combining step 5 and step 6 we use an iteration calculation method to approach to 1992's actual value. 


\section{c). GDP of each City (Step 3)}

In China both, regional government and city government make detailed plans for their economic growth. So in this study we can use the planned economic growth rate to estimate the GDP of 1992 from the GDP of 1990.

d). Attraction and Distribution Models (Step 5, 6, 7,8)

In the attraction model, we use foreign production output as one factor to calculate attraction for foreign investment. But the output is actually a result of the distribution of foreign investment. Therefore, the attraction model and distribution model are used iteratively. As shown in step 5 in Figure 9, after $\Delta Z_{1}$ is calculated we can obtain the first round value of foreign investment in the whole studied region $Z^{t}$, Then we will distribute this $Z^{t}$ in this region to get $Z_{i}^{t}$. In this distribution process the location probability can be calculated by the a logit model. We can use foreign investment data to represent the location glamorous for estimating formation (9). The estimated results of parameters of equation (17) which is a logarithm formation of equation (9) is given in Table 4 and Figure 11 with a high goodness of fit.

$$
\ln \pi_{i}=\alpha+\beta_{1} \ln \left(T_{i}\right)+\beta_{2} \ln \left(E_{i}\right)+\beta_{3} \ln \left(L_{i}\right)
$$

Table 4 Estimated Parameters (19)

\begin{tabular}{|c|l|c|c|c|}
\hline & $\alpha$ & $\beta_{1}$ & $\beta_{2}$ & $\beta_{3}$ \\
\hline Value & -2.18 & -1.14 & 2.12 & 0.81 \\
\hline T-value & -0.6 & -3.06 & 2.29 & 2.18 \\
\hline $\mathrm{R}$ & \multicolumn{4}{|c|}{0.94} \\
\hline Sample & \multicolumn{4}{|c}{11} \\
\hline
\end{tabular}

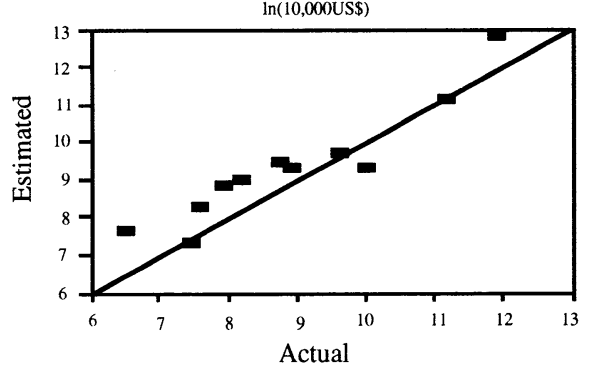

Figure 11 Comparison of Estimated and Actual Value of Location Utility Sub-model

Then with the model we are able to calculate the increased output $\Delta P_{i}$ and increased attraction $\Delta A t t$. From here we can continue iteration calculation until the $\Delta Z_{k}$ of round $k$ is less than a given tolerance. Theoretically the tolerance should be small enough for getting a correct results. The total foreign investment in 1992 is about 1.9 billion US\$, the error will be $0.003 \%$ if the tolerance is 50,000 US $\$$. Therefore we think 50,000 US\$ as the tolerance is small enough in this study. After 32 times iteration from step 5-10, $\Delta Z_{k}$ became smaller than the given tolerance. We obtained simulation results as Figure 12. It may be said that in this study the iteration from step 5-10 converged well. However whether this iteration always converges or not is not discussed here.

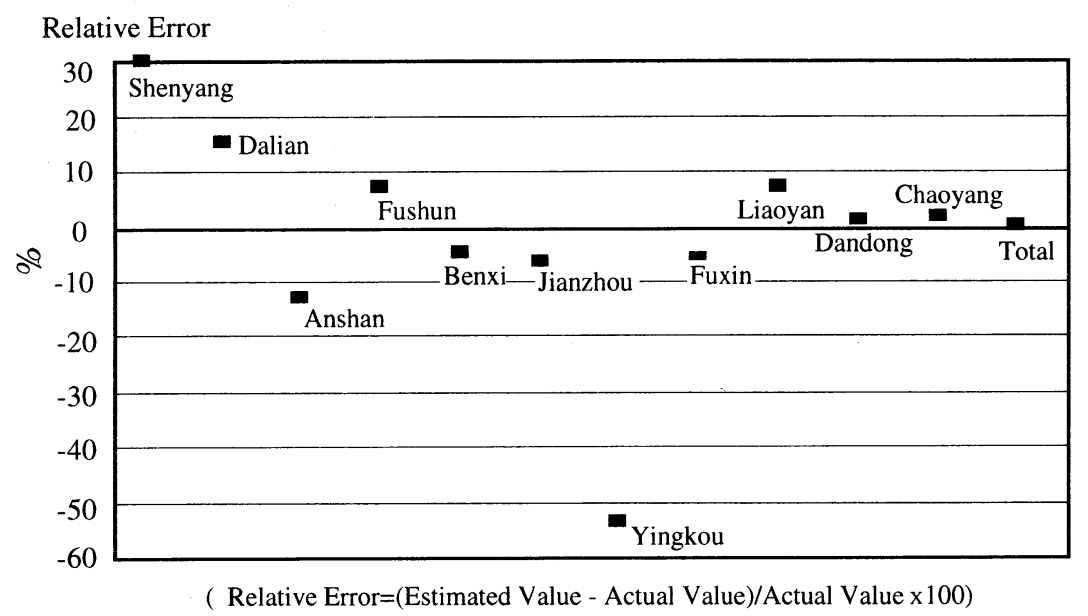

Figure 12 Relative Error of Estimated Foreign Investment in Each City

Within 11 cities, relative errors are less than $14 \%$ except two cities. Error of Shenyang is over $30 \%$. For Yingkou city the error is much bigger (about $-55 \%$ ). This is because this city is another harbor city and has recently developed very quickly.

(3). Expressway's Effects on Foreign Investment (Step 9, 10). 
By lessening $Z^{t 0}$ from $Z^{t 1}$ (step 10), we can obtain the effects of expressway on foreign investment as the difference between the with and without cases. The values are shown in Table 5.

In Figure 13 we depict two kinds of simulated results and the actual data of foreign investment in Liaoning in 1992. From this figure the following matters can be understood

1) Our model can forecast the changed amount of foreign investment resulted from expressway construction.

2) Our model can also reveal that because of the expressway construction, the foreign investment along the expressway increases faster than in other area.

3) Our model overestimated the amount of foreign investment in one terminal of the expressway in harbor city (Dalian), and underestimated the amount of foreign investment in another terminal of expressway in inland city (Shenyang).

4) Our model can not estimate the changed attraction for foreign investment which is caused by city self. This is why the relative error of Yingko is quit big.

Table 5 Effects of Expressway on Foreign Investment (Million US\$)

\begin{tabular}{|c|c|c|c|c|c|c|}
\hline City & Shenyang & Dalian & Anshan & Fushun & Benxi & Jinzhou \\
\hline$\Delta Z_{i}$ & 10.2 & 57.3 & 1.5 & 0.8 & 0.3 & 0.2 \\
\hline City & Yingkou & Fusin & Liaoyang & Dandong & Chaoyang & Total \\
\hline$\Delta Z_{i}$ & 2.2 & 0.02 & 0.7 & -0.3 & 0.02 & 74.03 \\
\hline
\end{tabular}

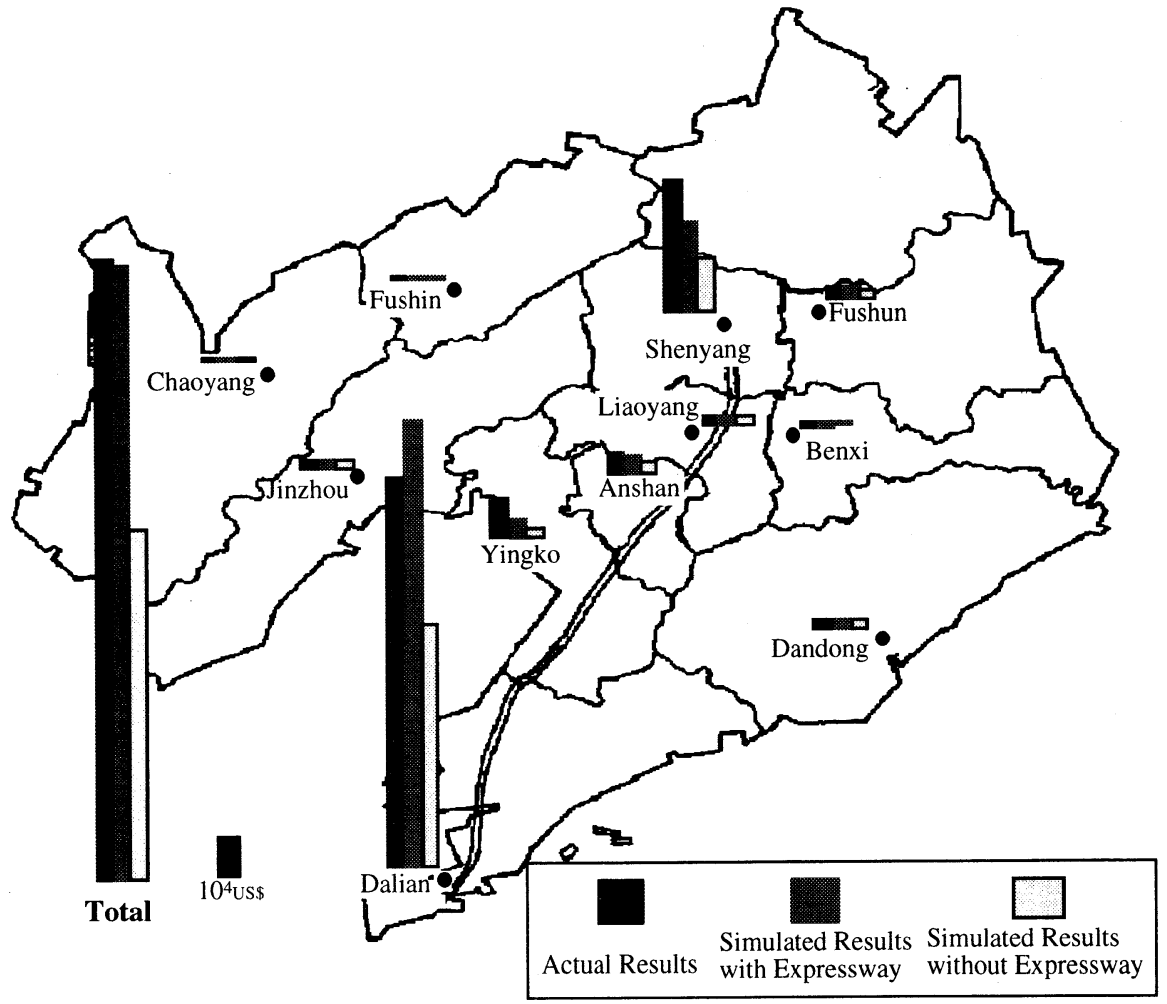

Figure 13 Foreign Investment in Each City in 1992

\section{Conclusion and Further Works}

In this study we analyzed the effect of expressway on foreign investment by models which were estimated using actual data. From the data, we found that road construction has two kinds of effects, namely attraction and distribution effects. We also pointed out that the attraction effect is caused by the increment of regional total accessibility and that the distribution effects resulted from the increment of accessibility between cities in the improved region. Considering the data limitation, we 
developed models for estimating these effects based on a single-equation approach. With this model we carried out a case study. From this simulation, we found that the total investment in this region in the case of with an expressway increased much faster that in the case of without an expressway. By comparing the simulated results with the actual data, we verified the usefulness of our model. We also found some shortcomings in our model, for example when estimating the distribution of Import-Export freight, it was impossible to consider the harbor's improvement. In addition, when we analyzed the effects on foreign investment, we mainly took hard conditions such as transportation time, telephone ownership, market scale or labor resources into account but neglected the soft one such as the service from government, attributes of the city and connection between people because of the limitation of data. Shenyang is the political, economic and culture central of Liaoning because it is the capital of this region. Therefore, for foreign investment it has much bigger attraction than non-capital city even which has the same city scale. As the result, the foreign investment there is under-estimated. In the case of Dalian, because there already has been too much foreign investment compared with other cities. The service of government is no so good as in other cities. The small and middle scale investment which can be accorded a cordial reception in other cities might be treaded coldly here. This is the reason why the foreign investment in Dalian is over-estimated. In order to solve this kind of problems, the dummy variables which can represent the soft condition and need much more information about each city are needed to introduce. We will carry out this kind of study in the future.

\section{References}

1) Peter Nijkamp \& Eddy Blaus (1993). Impact Assessment and Evaluation in Transportation Planning, Kluwer Academic Publishers.

2) Moshe Ben-Akiva \& Steven R. Lerman (1985). Discrete Choice Analysis, The MIT Press.

3) Statistic Year Book of Liaoning Province (1991, 1993, 1994). Chinese Statistic Publisher.

4) Chinese Transportation Statistic Year Book (1989-1993). Chinese Statistic Publisher

5) Japan-Sino Northeast Area Development Society. Investment Condition of each City in Liaoning Province (1993).

6). Yoshitsugu HAYASHI (1986). Modeling the Long-term Effects of Transport and Land Use Policies on Industrial Location Regional Science and Urban Economics 16 pp123-143 North-Holland

7). Yoshitsugu HAYASHI (1984). An Alternative Approach of Industrial Location Modeling by Means of Disaggregate Models Infrastructure Planning Review No.1

中国における外国投資に対する道路整備の発生及び分布の効果のモデル化*

\section{林 良嗣 ${ }^{* *}$ 楊 忠振 ${ }^{* * *}$}

現在、中国において合理的な道路整備を行うために道路の投資一便益の分析をすることは重要になっている。本 研究の目的は、高速道路整備の効果とそれに伴う外国投資の変化を予測できるモデルを開発する。ここでデータの 制䄪を考え、Single-Equation Approachを用い外国投資に対する発生と分布の効果を定式化している。その後、シ ミュレーションを行い、このモデルの正確さと適用性を確かめる。

\section{MODELING THE EFFECTS OF ROAD CONSTRUCTION ON THE ATTRACTION AND REGIONAL DISTRIBUTION OF FOREIGN INVESTMENT IN CHINA*}

\section{by Yoshitugu HAYASHI**, Yang Zhong-Zhen***}

Recently in China, benefit analysis of road improvement has become very important in order to rationalize the investment. The aim of this study is to develop a model which can predict the effect of expressway construction on foreign investment which is considered as an accelerator for regional economic growth. Considering the data limitation, based on a single-equation approach, we model the attraction and distribution effects of expressway construction on foreign investment. Then we describe the simulate process using the developed model. As a result, we verified the correctness and usefulness of this model. 